\title{
PENGARUH LAMA WAKTU PERENDAMAN EMBRIO DI DALAM LARUTAN $17 \alpha$-METILTESTOSTERON TERHADAP NISBAH KELAMIN IKAN TETRA KONGO (Micralestes interruptus)
}

\begin{abstract}
Asda Laining *
ABSTRAK

Ikan tetra kongo (Micralestes interruptus) merupakan salah satu jenis ikan hias bernilai ekonomis tinggi, khususnya ikan jantan. Oleh sebab itu, perlu upaya untuk memperoleh keturunan kelamin tunggal jantan melalui perendaman telur dengan menggunakan hormon $17 u-$ metiltestosteron. Penelitian ini bertujuan untuk mengetahui pengaruh lama waktu perendaman telur dengan menggunakan hormon $17 \alpha$-metiltestosteron terhadap nisbah kelamin ikan tetra kongo. Lama waktu perendaman telur yang dicobakan adalah 2, 4, 6, dan 8 jam dengan konsentrasi $25 \mathrm{mg} / \mathrm{L}$. Perendaman dimulai pada saat embrio mencapai fase bintik mata. Ikan uji dipelihara sampai berumur tiga bulan untuk dianalisis jenis kelaminnya. Berdasarkan identifikasi morfologi, persentase ikan jantan cenderung meningkat dengan semakin lamanya waktu perendaman. Persentase ikan jantan yang diperoleh pada kontrol, 2 ,4, 6, dan 8 jam perendaman masing-masing adalah 50,26;49,97;60,97; 65,49; dan 89,08\%. Hasil pemeriksaan gonad selain ikan jantan dan betina, ditemukan pula ikan hermaprodit pada setiap perlakuan kecuali kontrol. Persentase ikan hermaprodit tersebut pada periakuan 2, 4, 6, dan 8 jam perendaman masingmasing adalah 3,$75 ; 3,62 ; 6,11$; dan $7,88 \%$. Daya tetas telur sebagai data pendukung pada kontrol, 2, 4, 6, dan 8 jam masing-masing adalah 93,67;75,11; 83,66; 72,22; dan 66,78\%. Hasil penelitian ini menunjukkan bahwa perlakuan perendaman selama 8 jam mempunyai efektivitas yang lebih tinggi dalam merangsang diferensiasi jenis kelamin dari betina menjadi jantan dibandingkan dengan perlakuan 2, 4, dan 6 jam pada konsentrasi 25 mg/L.
\end{abstract}

ABSTRACT: The effect of $17 \alpha$-methyltestosterone hormone immersion on embryonic stage masculinization of congo tetra (Micralestes interruptus) around. By: Asda Laining

Congo tetra is an economically important ornamental fish where the male has better prices compared to the female. In order to make this business more profitable, an effort to obtain malemonosex offspring is needed. The experiment aimed to determine the effect of immersion duration of embryonic stage in $17 \alpha$-methyltestosterone hormone solution on masculinization of kongo tetra. Immersion duration were 2, 4, 6, dan 8 hours at 25 mg/L hormone concentration. Immersion was started at eyed stage of embryo. Newly-hatched larvae were reared up to three months where sexing was easily done based on morphological characteristics. Identification based on morphological feature was also confirmed with histological analysis by asetocarmine method. The results showed that there was a significantly effect $(P<0.05)$ of immersion duration of $17 \alpha$ methyltestosterone on the percentage of male. The average male percentage based on morphological feature in control (none of hormone treatment), 2, 4, 6, and 8- $h$ were 50.27, 49.97, 60.97. 65.49, and 89.08\% respectively. Histological identification showed the existence of hermaphrodite group other than male and female in hormone treated fish. The percentage of hermaphrodite fish found from short to long duration time of immersion were 3.75, 3.62, 6.11, and $7.88 \%$, respectively. Hatching rate as an additional data in control, 2, 4, 6, and 8- $h$ were 93.67. $75.11,83.66,72.22$, and $66.78 \%$. Eight hours immersion was most effective than the other treatments to induced sex reversal from female to male at $25 \mathrm{mg} / \mathrm{L}$ concentration.

KEYWORDS: $\quad$ Micraleptes interruptus, $17 \alpha$-methyltestosterone hormone, immersion duration, sex reversal

\section{PENDAHULUAN}

Ikan tetra kongo (Micralestes interruptus) merupakan salah satu ikan hias bernilai ekonomis tinggi dan banyak terdapat di pasaran. Ikan tetra kongo jantan lebih indah daripada betinanya, sehingga nilai ekonomisnya pun lebih tinggi. Keindahan ikan ini

berhubungan dengan sisiknya yang memantulkan warna pelangi cerah yang sangat indah. Di bawah cahaya lampu, ikan jantan biasanya memancarkan cahaya yang berwarna emas dan turqouise sedangkan warna tubuh ikan betina tidak terlalu menarik (Axelrod, 1971; Mills, 1986). Oleh karena itu,

\footnotetext{
Peneliti pada Balai Penelitian Perikanan Pantai
} 
dalam budi dayanya ikan tetra kongo jantan lebih disukai daripada betinanya.

Pengubahan kelamin (sex reversal) merupakan salah satu teknik yang dapat dilakukan untuk memperoleh keturunan monoseks jantan. Hormon yang dapat digunakan adalah steroid androgen misalnya testosteron. Derivat dari hormon ini yang merupakan hormon steroid sintetis dan telah berhasil digunakan dalam merangsang perubahan jenis kelamin dari betina menjadi jantan adalah hormon $17 \alpha$-metiltestosteron. Menurut Yamazaki (1983), hormon androgen sintetis memiliki efektivitas yang lebih tinggi dibandingkan yang alami, perkecualian pada hormon testosteron propionat. Hal ini terjadi karena hormon $17 \alpha$-metiltestosteron dapat bereaksi lebih lama pada target sel dibandingkan dengan androgen alami (Martin, 1979; Donaldson \& Benfey, 1987), sesuai dengan pengujian yang dilakukan oleh Fugerlund \& Mc. Bride dalam Hunter \& Donaldson (1983) yang menunjukkan bahwa metiltestosteron dieliminasi lebih lambat daripada testosteron

Metiltestosteron pada ikan jantan meningkatkan spermatogenesis, sedangkan pada betina mendorong timbulnya karakter sekunder seks jantan, misalnya perpanjangan sirip anal pada ikan gapi (Matty, 1985). Sedangkan menurut Piferrer \& Donaldson (1991), hormon ini menyebabkan reabsorbsi telur dan degenerasi ovari.

Untuk memperoleh perendaman yang efektif yang perlu diperhatikan adalah hubungan antara konsentrasi dan lama perlakuan. Berbagai percobaan mengenai perbedaan dosis menunjukkan bahwa ada kisaran dosis optimum yang harus diberikan, sehingga pengubahan kelamin dapat terjadi secara sempurna. Dzwillo dalam Hunter \& Donaldson (1983) berhasil menjantankan ikan gapi (Poecilia reticulata) dengan menggunakan hormon $17 \alpha$-metiltestosteron $3 \mathrm{mg} / \mathrm{L}$ selama 24 jam perendaman pada fase embrio. Pada ikan salmon dosis yang optimum adalah 0,2 mg/L melalui perendaman selama 120 menit.

Pengubahan kelamin melalui pemberian hormon dapat dilakukan dengan suntikan (Mirza \& Shelton, 1988), perendaman (Yamazaki, 1983; Baker et al., 1988; Piferrer \& Donaldson, 1989) atau secara oral (Eckstein \& Spira dalam Hepher \& Pruginin, 1981; Nagy et al., 1981). Pemberian secara oral mudah dilakukan tetapi terbatas hanya pada ikan yang dapat menerima pakan buatan dan steroid kemungkinan dapat mengalami pencucian (leaching) selama di dalam air. Pemberian hormon melalui bioenkapsulasi artemia membutuhkan jumlah hormon yang lebih sedikit, tetapi dari segi teknisnya cara ini kurang praktis karena perendaman artemia dilakukan setiap waktu saat larva akan diberi pakan. Di samping itu pada ikan tertentu misalnya pada ikan salmon, di mana diferensiasi seks jantan dimulai sebelum ikan mulai makan, maka prosedur yang digunakan adalah perendaman alevin dalam larutan hormon (Yamazaki. 1983) atau perendaman telur pada stadia bintik mata (Baker et al., 1988; Piferrer \& Donaldson, 1989). Pènelitian ini bertujuan untuk mengetahui pengaruh lama waktu perendaman telur dengan menggunakan hormon $17 \alpha$-metiltestosteron terhadap nisbah kelamin ikan tetra kongo.

\section{BAHAN DAN METODE}

Induk ikan dipelihara dalam akuarium berukuran $100 \times 50 \times 50 \mathrm{~cm}^{3}$ terpisah antara jantan dan betina Induk diberi makanan berupa cuk merah (larva Chironomus) beku 3 kali sehari secara satiasi Setelah mencapai kematangan gonad, induk dipijahkan secara massal dalam akuarium berukuran $60 \times 50 \times 50 \mathrm{~cm}^{3}$ dengan perbandingan antara jantan dan betina adalah 3:5. Telur dari hasil pemijahan dapat disifon dengan mudah karena telur ikan in sifatnya tenggelam di dasar akuarium. Setelah mencapai stadia bintik mata, sekitar 48-50 jam dari pembuahan, telur dihitung dan ditempatkan dalam mangkok bervolume 0,5 L yang berisi larutan hormon. Hormon diberikan dengan cara melarutkannya ke dalam alkohol $70 \%$ sebanyak $1 \mathrm{~mL}$ kemudian dimasukkan ke wadah perendaman. Hormon yang digunakan adalah $17 \alpha$-metiltestosteron ( $17 \alpha$-methyl 4-androsteron-17-OI-3 one), $17 \alpha$-MT dengan rumus kimia $\mathrm{C}_{20} \mathrm{H}_{30} \mathrm{O}_{2}$. Hormon ini berwarna putih dan berbentuk serbuk halus (powder). Konsentrasi hormon yang digunakan adalah $25 \mathrm{mg} / \mathrm{L}$

Percobaan ini terdiri atas satu kontrol dan 4 perlakuan dengan 3 ulangan yang disusun berdasarkan rancangan acak lengkap. Perlakuan yang dimaksud adalah lama waktu perendaman yaitu $2,4,6$, dan 8 jam. Konsentrasi hormon yang digunakan adalah 25 $\mathrm{mg} / \mathrm{L}$. Telur yang telah diberi perlakuan perendaman sebanyak 60 butir dimasukkan ke dalam akuarium $25 \times 25 \times 25 \mathrm{~cm}^{3}$ untuk diinkubasi dan diamati ada tidaknya telur yang mati. Untuk mencegah timbulnya jamur pada telur-telur selama inkubasi, media diberi larutan biru metilen $5 \mathrm{mg} / \mathrm{L}$

Makanan untuk larva mulai diberikan pada saat kuning telur akan habis. Makanan yang diberikan berupa naupli artemia sampai ikan berumur dua minggu, kemudian diberi cacing rambut (Tubificid) sampai anak ikan berumur tiga bulan. Pemberian pakan dilakukan 3 kali sehari secara satiasi. Untuk menjaga kualitas air dilakukan penyifonan 2 atau 3 hari sekali dan penggantian air $1 / 3$ bagian 2 minggu sekali. Air yang digunakan adalah air yang telah diendapkan selama 1 hari. 
Parameter utama yang diuji dalam percobaan ini adalah persentase ikan jantan dan ikan betina setelah perendaman telur. Pengamatan dilakukan setelah ikan berumur tiga bulan. Selain itu, dihitung pula persentase daya tetas telur sebagai parameter pendukung. Pengamatan terhadap daya tetas telur dilakukan setelah dua hari perlakuan.

Penentuan jenis kelamin hasil percobaan dilakukan berdasarkan pengamatan karakter kelamin sekunder (penampakan morfologi) dan secara histologis. Identifikasi jenis kelamin ikan muda berdasarkan morfologi dilakukan setelah ikan berumur tiga bulan, karena pada umur kurang dari tiga bulan perbedaan morfologi ikan tetra kongo jantan dan betina masih sulit dibedakan. Meskipun pada umur sekitar dua bulan perbedaan tersebut mulai terlihat. Pada umur tiga bulan, bagian tubuh yang khas membedakan kedua jenis kelamin ikan tetra kongo adalah sirip ekor. Pada ikan jantan muda sirip ekornya memiliki rumbai hanya satu dan pendek. Berbeda dengan ikan jantan dewasa, sirip ekornya berumbai dua dan panjang serta sirip punggungnya memanjang sampai menyentuh sirip ekornya. Morfologi ikan betina muda, khususnya bentuk ekor, sama dengan betina dewasa yaitu berlekuk tunggal dan tidak memiliki rumbai. Sirip punggungnya tidak mengalami perpanjangan seperti pada ikan jantan. Rumbai yang terdapat pada sirip ekor ikan jantan merupakan perpanjangan jari-jari sirip, sedangkan pada betina jari-jari sirip ekornya tidak memanjang (Bird, 1986; Lingga \& Susanto, 1991)

Penentuan jenis kelamin secara histologis dilakukan dengan cara pemeriksaan jaringan gonad melalui pewarnaan dengan asetokarmin (Guerrero \& Shelton, 1974). Ikan uji dibedah dan diambil gonadnya lalu diletakkan di atas gelas objek. Gonad dicincang sampai halus dan diberi beberapa tetes larutan asetokarmin dan dibiarkan beberapa menit. Gelas penutup diletakkan dengan penekanan secara perlahan-lahan. Preparat yang sudah siap diamati dengan menggunakan mikroskop

Penentuan jenis kelamin berdasarkan Komen et al. (1989) adalah sebagai berikut:

1. Jantan: Jaringan gonad mengandung sel bakal sperma (testis)

2. Betina: Jaringan gonad mengandung sel bakal telur (ovari)

3. Hermaprodit: Jaringan gonad mengandung sel bakal sperma dan sel bakal telur

4. Steril: Jaringan gonad berbentuk seperti benang dan mengandung lembaran jaringan penghubung di dalamnya sering mengandung oosit maupun spermatogonia dalam fase perkembangan yang terhambat.
Selanjutnya, data yang diperoleh dari hasil pengamatan dianalisis dengan anova dan uji lanjut dengan Duncan Multiple Test. Data yang dianalisis disajikan dalam bentuk tabel.

\section{HASIL DAN BAHASAN}

Pada umur tiga bulan sirip ekor ikan tetra kongo sudah dapat dijadikan ciri pembeda di mana sirip ekor ikan jantan berumbai satu, sedangkan ikan betina hanya bercagak tanpa rumbai. Apabila ikan ini dipelihara sampai dewasa dan matang gonad, maka ciri morfologi pembeda antara jantan dan betina akan semakin jelas di mana ikan jantan sirip punggungnya akan berkembang dan memanjang yang bisa sampai menyentuh sirip ekornya. Berbeda dengan ikan betina dewasa yang morfologi tubuhnya tidak jauh berbeda dengan ikan yang masih muda. Pada umur ini ikan jantan akan tampak semakin indah.

Jumlah ikan berdasarkan nisbah kelamin disajikan pada Tabel 1. Pada Tabel tersebut terlihat bahwa persentase ikan berkelamin jantan pada kontrol dan perlakuan perendaman selama $2,4,6$, dan 8 jam berturut-turut adalah $50,26 \% ; 49,97 \%$; 60,97\%; $65,49 \%$; dan 89,08\%. Hasil ini menunjukkan bahwa persentase ikan berkelamin jantan meningkat seiring dengan peningkatan lamanya perendaman telur di dalam hormon $17 \alpha-\mathrm{MT}$. Hal yang sebaliknya terjadi pada persentase ikan berkelamin betina. Persentase ikan berkelamin jantan dan betina pada kontrol cenderung sama yaitu 50,26 dan 49,74\%. Hal ini menunjukkan bahwa pada ikan tetra kongo sifat genetik penentu kelaminnya seimbang. Hal ini sesuai dengan pernyataan Petrovicky (1988) bahwa nisbah kelamin ikan tetra kongo adalah 1:1.

Dari Tabel 1 terlihat bahwa ikan berkelamin jantan tertinggi yaitu $89,09 \%$ diperoleh pada perlakuan perendaman 8 jam. Tingginya persentase ini diduga karena jumlah hormon yang diserap selama 8 jam pada stadia bintik mata mampu mempengaruhi diferensiasi kelamin embrio. Hal yang serupa diperlihatkan pula pada hasil penelitian Dzwillo dalam Hunter \& Donaldson (1983) yang berhasil menjantankan ikan gapi (Poecilia reticulata) melalui perendaman di dalam larutan hormon $17 \alpha-$ MT 3 mg/L selama 24 jam pada stadia embrio. Piferrer \& Donaldson (1991) berhasil pula memperoleh $73,1 \%$ ikan salmon jantan dengan perendaman stadia bintik mata selama 2 jam dengan konsentrasi 0,4 mg/L. Bahkan, Baker et al. (1988) mampu mendapatkan $100 \%$ ikan salmon jantan hanya dengan merendam telur selama 2 jam dengan konsentrasi 0,2 mg/L.

Pada perlakuan selama 2 jam perendaman diduga hormon yang terserap ke dalam telur belum mencukupi dalam perangsangan diferensiasi kelamin dari betina 
Tabel 1. Jumlah anak ikan menurut jenis kelaminnya berdasarkan identifikasi morfologi Table 1. Number of male and female offspring based on morphological classification

\begin{tabular}{|c|c|c|c|c|c|}
\hline $\begin{array}{l}\text { Lama perendaman } \\
\text { Duration of immersion }\end{array}$ & $\begin{array}{l}\text { Ulangan } \\
\text { Replicate }\end{array}$ & $\begin{array}{l}\text { Jantan } \\
\text { male (\%) }\end{array}$ & $\begin{array}{c}\text { Rata-rata } \\
\text { Average }(\%)\end{array}$ & $\begin{array}{l}\text { Betina } \\
\text { Female (\%) }\end{array}$ & $\begin{array}{c}\text { Rata-rata } \\
\text { Average (\%) }\end{array}$ \\
\hline \multirow{3}{*}{$\begin{array}{l}\text { Kontrol } \\
\text { Control }\end{array}$} & 1 & 47.17 & \multirow{4}{*}{$50.26^{a}$} & 52.17 & \multirow{3}{*}{49.74} \\
\hline & 2 & 52.94 & & 47.06 & \\
\hline & 3 & 50.00 & & 50.00 & \\
\hline \multirow{3}{*}{$\begin{array}{l}2 \text { jam } \\
2 \text { hours }\end{array}$} & 1 & 43.75 & & 56.25 & \multirow{3}{*}{50.03} \\
\hline & 2 & 60.00 & \multirow[t]{2}{*}{$49.97^{a}$} & 40.00 & \\
\hline & 3 & 46.15 & & 53.85 & \\
\hline \multirow{3}{*}{$\begin{array}{l}4 \text { jam } \\
4 \text { hours }\end{array}$} & 1 & 54.35 & \multirow{3}{*}{$60.97^{b}$} & 45.65 & \multirow{3}{*}{39.03} \\
\hline & 2 & 66.67 & & 33.33 & \\
\hline & 3 & 61.91 & & 38.10 & \\
\hline \multirow{3}{*}{$\begin{array}{l}6 \text { jam } \\
6 \text { hours }\end{array}$} & 1 & 73.33 & \multirow{3}{*}{$65.49^{b}$} & 26.67 & \multirow{3}{*}{43.51} \\
\hline & 2 & 60.00 & & 40.00 & \\
\hline & 3 & 63.16 & & 36.84 & \\
\hline \multirow{3}{*}{$\begin{array}{l}8 \text { jam } \\
8 \text { hours }\end{array}$} & 1 & 95.45 & \multirow{3}{*}{$89.08^{c}$} & 4.50 & \multirow{3}{*}{10.90} \\
\hline & 2 & 77.78 & & 22.22 & \\
\hline & 3 & 94.00 & & 6.00 & \\
\hline
\end{tabular}

menjadi jantan. Persentase jantan yang diperoleh pada perlakuan ini relatif sama dengan kontrol, di mana uji lanjut dari analisis ragam memperlihatkan perbedaan yang tidak nyata $(P>0,05)$. Hal ini menunjukkan bahwa perendaman 2 jam pada konsentrasi hormon sebanyak $25 \mathrm{mg} / \mathrm{L}$ belum efektif. Berbeda pada perlakuan 4 dan 6 jam, persentase jantan lebih tinggi dibandingkan dengan kontrol. Diduga hormon yang diserap selama 4 dan 6 jam sudah mampu mengarahkan diferensiasi kelamin. Akan tetapi dari analisis ragam uji lanjut memperlihatkan perbedaan yang tidak nyata $(P>0,05)$ antara perendaman 4 dan 6 jam.

Hunter \& Donaldson (1983) mengemukakan bahwa gonad akan terkena hormon steroid lebih lama dibandingkan dengan lama pemberian hormon tersebut. Faktor yang mempengaruhi adalah dosis hormon steroid, kecepatan penyerapan, dan lamanya hormon di dalam gonad. Untuk memperoleh perendaman yang efektif yang perlu diperhatikan adalah hubungan antara konsentrasi dan lama perendaman. Umumnya perendaman dengan dosis yang tinggi membutuhkan waktu perendaman yang lebih singkat (Piferrer et al., 1994), begitupun sebaliknya (Carman et al., 1998).

Penyerapan hormon ke dalam telur diduga terjadi melalui difusi. Penambahan hormon ke dalam media perendaman menyebabkan adanya perbedaan konsentrasi hormon di dalam telur dengan di dalam media, yang selanjutnya menyebabkan terjadinya difusi sederhana. Besarnya laju difusi berkaitan dengan tingkat permeabilitas membran telur yang dipengaruhi oleh beberapa faktor yaitu perkembangan larva, komposisi media, suhu, perbandingan antara luas permukaan dan volume telur, serta ada tidaknya saluran membran (Alderdice, 1988)

Gonad ikan muda terletak di dalam rongga badan memanjang dari depan gelembung renang dan berakhir di lubang genital. Sepasang gonad ini berukuran sangat kecil sehingga hanya menyerupai benang tipis yang memanjang. Dari hasil pemeriksaan gonad diperoleh ikan jantan, ikan betina, dan ikan hermaprodit (Tabel 2). Ovari ikan tetra kongo terdiri atas sejumlah sel bakal telur dengan inti dan sitoplasmanya. Pada pembesaran 400x, sel telur dan organelanya (inti dan sitoplasma) tampak jelas. Dengan pewarnaan asetokarmin, inti nampak berwarna pucat sedangkan sitoplasma mengelilingi inti dengan warna merah.

Pada pembesaran $850 x$, terlihat sejumlah sel bakal sperma di dalam testes ikan tetra kongo dengan ukuran yang lebih kecil dibanding sel bakal telur. Sel bakal sperma ini tampak hanya berupa bintik-bintik merah yang menyebar. Tabel 2 menyajikan persentase ikan hermaprodit yang diperoleh dari pemeriksaan gonad. Pada tabel tersebut diketahui bahwa pada kontrol tidak ditemukan ikan hermaprodit. Pada perlakuan perendaman selama 2 jam persentase ikan hermaprodit yang diperoleh adalah 3,75\%. Nilai in lebih tinggi dibandingkan dengan persentase pada perlakuan perendaman selama 4 jam yaitu $3,62 \%$. Selanjutnya, pada perlakuan perendaman selama 6 dan 8 jam diperoleh ikan hermaprodit berturut-turut 
Tabel 2 Jumlah ikan hermaprodit berdasarkan histologi

Tabel 2 Number of hermaphrodite based on histology

\begin{tabular}{|c|c|c|c|c|c|c|}
\hline \multirow{2}{*}{$\begin{array}{c}\text { Lama perendaman } \\
\text { Duration of } \\
\text { immersion }\end{array}$} & \multirow[b]{2}{*}{$\begin{array}{l}\text { Ulangan } \\
\text { Replicate }\end{array}$} & \multicolumn{5}{|c|}{ Status gonad (Gonadal status) Hermaprodit (Hermaphrodite) } \\
\hline & & $\begin{array}{c}\text { Morfologi } \\
\text { Morphology } \\
(\%)\end{array}$ & $\begin{array}{l}\text { Rata-rata } \\
\text { Average } \\
(\%)\end{array}$ & $\begin{array}{c}\text { Morfologi } \\
\text { Morphology } \\
\text { (\%) }\end{array}$ & $\begin{array}{l}\text { Rata-rata } \\
\text { Average } \\
(\%)\end{array}$ & $\begin{array}{c}\text { Tot. hermaprodite } \\
\text { Tot. of hermaphrodite } \\
(\%)\end{array}$ \\
\hline \multirow{3}{*}{$\begin{array}{l}\text { Kontrol } \\
\text { Control }\end{array}$} & 0 & 0 & & 0 & & \\
\hline & 0 & 0 & $50.26^{\mathrm{a}}$ & 0 & 0 & 0 \\
\hline & 0 & 0 & & 0 & & \\
\hline \multirow{3}{*}{$\begin{array}{l}2 \text { jam } \\
2 \text { hours }\end{array}$} & 3.13 & & & 3.13 & & \\
\hline & 0 & 2.71 & $49.97^{a}$ & 0 & 1.04 & 3.75 \\
\hline & 5.00 & & & 0 & & \\
\hline \multirow{3}{*}{$\begin{array}{l}4 \text { jam } \\
4 \text { hours }\end{array}$} & 6.52 & & & 4.35 & & \\
\hline & 0 & 2.17 & $60.97^{b}$ & 0 & 1.45 & 3.62 \\
\hline & 0 & & & 0 & & \\
\hline \multirow{3}{*}{$\begin{array}{l}6 \mathrm{jam} \\
6 \text { hours }\end{array}$} & 8.33 & & & 0 & 0 & \\
\hline & 0 & 6.11 & $65.49^{b}$ & 0 & 0 & 6.11 \\
\hline & 10.00 & & & 0 & 0 & \\
\hline \multirow{3}{*}{$\begin{array}{l}8 \text { jam } \\
8 \text { hours }\end{array}$} & 13.64 & & & 0 & 0 & \\
\hline & 0 & 7.88 & $89.08^{c}$ & 0 & 0 & 7.88 \\
\hline & 10.00 & & & 0 & 0 & \\
\hline
\end{tabular}

adalah $6,11 \%$ dan $7,88 \%$. Adanya ikan hermaprodit menunjukkan bahwa hormon yang diberikan melalui perendaman berpengaruh terhadap perkembangan gonad. Gonad ikan hermaprodit terdiri atas sejumlah sel bakal telur dan sel bakal sperma. Banyaknya sel bakal telur dan sel bakal sperma pada setiap ikan tidak selalu sama. Sel bakal telur kadang terlihat lebih banyak daripada sel bakal sperma, dan sebaliknya. Pada Tabel 2 terlihat bahwa morfologi ikan hermaprodit ada yang sama dengan morfologi ikan jantan dan ada pula yang sama dengan morfologi ikan betina. Fenomena ini ditemukan pada perlakuan perendaman selama 2 dan 4 jam. Pada perlakuan perendaman selama 6 dan 8 jam morfologi ikan hermaprodit yang ditemukan hanya yang sama dengan ikan jantan.

Persentase ikan jantan yang diperoleh pada percobaan ini belum maksimal karena belum diperoleh persentase sebesar $100 \%$. Hal yang sama terjadi pula pada feminisasi Oreochromis sp. dengan perendaman dalam $17 \beta$-estradiol selama 12 jam pada konsentrasi $200 \mu \mathrm{g} / \mathrm{L}$ yang hanya memperoleh ikan betina sebesar 83,5\% (Carman et al., 1998). Begitupun dengan percobaan Hopkins et al. (1979) pada O. niloticus dengan hormon yang sama dengan konsentrasi 25 $200 \mathrm{mg} / \mathrm{L}$ selama 9-11 minggu hanya mendapatkan ikan betina sebanyak $60 \%-70 \%$. Belum maksimalnya hasil yang diperoleh diduga karena lama perlakuan dan konsentrasi hormon yang diaplikasikan belum tepat.
Tabel 3 memperlihatkan bahwa kontrol memiliki daya tetas tertinggi, yaitu $93,11 \%$. Pada perlakuan perendaman selama 2 jam, persentase daya tetas diperoleh $75,11 \%$. Nilai ini lebih rendah jika dibandingkan dengan kontrol dan perlakuan 4 jam perendaman yaitu $83,66 \%$. Selanjutnya, pada perlakuan 6 dan 8 jam perendaman, persentase daya tetasnya berturutturut adalah $72,22 \%$ dan $66,78 \%$. Hasil ini menunjukkan bahwa semakin lama waktu perendaman, menyebabkan daya tetas telur semakin menurun. Pemberian hormon diduga menekan proses embriogenesis. sehingga pertumbuhan somatik terganggu yang menyebabkan embrio cacat dan akhirnya mati sebelum menetas. Carman et al. (1998) pada percobaan dengan menggunakan tiga jenis hormon steroid pada ikan Oreochromis sp. memperoleh laju sintasan antara $68 \%-90 \%$

Percobaan yang dilakukan oleh Shelton \& Jensen dalam Hunter \& Donaldson (1983) menunjukkan bahwa penggunaan hormon $17 \alpha$-MT pada ikan koan (Ctenopharyngodon idella) secara oral dengan dosis $120 \mathrm{mg} / \mathrm{kg}$ pakan selama 255 hari menyebabkan pertumbuhan dan perkembangan gonad terhambat. Fenomena yang sama terjadi pada pemberian hormon secara implantasi dengan laju difusi 18,7 g/hari selama 303 hari. Arma et al. (1995) menyatakan bahwa waktu melahirkan dan jumlah anak yang dilahirkan oleh induk gapi (Poecilia reticulata) cenderung menurun dengan meningkatnya waktu pemberian hormon $17 \alpha-\mathrm{MT}$ dengan dosis $400 \mathrm{mg} / \mathrm{L}$ 
Tabel 3. Jumlah telur dan persentase daya tetas telur ikan tetra kongo

Table 3. Number of eggs and percentages of hatching rate of kongo tetra

\begin{tabular}{|c|c|c|c|c|c|}
\hline $\begin{array}{l}\text { Lama perendaman } \\
\text { Duration of immersion }\end{array}$ & $\begin{array}{l}\text { Ulangan } \\
\text { Replicates }\end{array}$ & $\begin{array}{l}\text { Jml. telur } \\
\text { No. of eggs } \\
\text { (pc) }\end{array}$ & $\begin{array}{l}\text { Jml. telur menetas } \\
\text { No. of hatched eggs } \\
(\mathrm{pc})\end{array}$ & $\begin{array}{l}\text { Daya tetas } \\
\text { Hatching rate } \\
\text { (\%) }\end{array}$ & $\begin{array}{c}\text { Rata-rata } \\
\text { Average } \\
(\%)\end{array}$ \\
\hline \multirow{3}{*}{$\begin{array}{l}\text { Kontrol } \\
\text { Control }\end{array}$} & 1 & 60 & 51 & 85.00 & \multirow{3}{*}{93.67} \\
\hline & 2 & 60 & 60 & 100.00 & \\
\hline & 3 & 60 & 58 & 96.00 & \\
\hline \multirow{3}{*}{$\begin{array}{c}2 \text { jam } \\
2 \text { hours }\end{array}$} & 1 & 60 & 48 & 80.00 & \multirow{3}{*}{75.11} \\
\hline & 2 & 60 & 47 & 78.33 & \\
\hline & 3 & 60 & 40 & 67.00 & \\
\hline \multirow{3}{*}{$\begin{array}{l}4 \text { jam } \\
4 \text { hours }\end{array}$} & 1 & 60 & 58 & 96.67 & \multirow{3}{*}{83.66} \\
\hline & 2 & 60 & 47 & 78.30 & \\
\hline & 3 & 60 & 46 & 67.00 & \\
\hline \multirow{3}{*}{$\begin{array}{l}6 \text { jam } \\
6 \text { hours }\end{array}$} & 1 & 60 & 40 & 66.67 & \multirow{3}{*}{72.22} \\
\hline & 2 & 60 & 36 & 60.00 & \\
\hline & 3 & 60 & 54 & 89.00 & \\
\hline \multirow{3}{*}{$\begin{array}{l}8 \text { jam } \\
8 \text { hours }\end{array}$} & 1 & 60 & 39 & 65.00 & \multirow{3}{*}{66.78} \\
\hline & 2 & 60 & 32 & 53.33 & \\
\hline & 3 & 60 & 49 & 82.00 & \\
\hline
\end{tabular}

Apabila hasil yang diperoleh pada Tabel 1 dibandingkan dengan Tabel 3 maka terlihat bahwa peningkatan lama perendaman cenderung meningkatkan persentase jantan, tetapi cenderung pula menurunkan daya tetas telur. Akan tetapi secara kuantitatif jumlah ikan jantan yang diperoleh pada perlakuan khususnya pada perendaman 8 jam masih tinggi dibandingkan dengan kontrol. Di samping itu untuk efisiensi pemakaian hormon, maka jumlah telur yang diberi perlakuan dapat ditingkatkan tanpa mengubah volume media perendaman.

Secara keseluruhan hasil penelitian ini memperlihatkan adanya kontradiksi antara persentase jantan dengan daya tetas telur di mana peningkatan lama perendaman cenderung meningkatkan persentase jantan tetapi cenderung pula menurunkan daya tetas telur. Oleh sebab itu perlu dikaji lebih lanjut hubungan antara lama perendaman dengan konsentrasi hormon yang diberikan.

\section{KESIMPULAN DAN SARAN}

\section{Kesimpulan}

1. Pemberian hormon $17 \alpha-M T$ dengan konsentrasi 25 $\mathrm{mg} / \mathrm{L}$ pada perendaman selama 8 jam mempunyai efektivitas yang lebih tinggi dalam merangsang diferensiasi jenis kelamin embrio dari betina menjadi jantan dibandingkan dengan perlakuan 2, 4, dan 6 jam.
2. Selain merangsang diferensiasi jenis kelamin, pemberian hormon $17 \alpha-\mathrm{MT}$ dapat pula menyebabkan terjadinya ikan hermaprodit.

3. Peningkatan lama perendaman cenderung menurunkan daya tetas telur.

\section{Saran}

Hubungan antara lama perendaman dengan dosis yang tepat perlu dikaji lebih lanjut, mengingat persentase ikan jantan yang diperoleh pada percobaan ini belum $100 \%$. Demikian pula halnya dengan masa diferensiasi kelamin ikan tetra kongo perlu diketahui dengan jelas, sehingga waktu awal pemberian hormon dapat dilakukan dengan tepat.

\section{UCAPAN TERIMA KASIH}

Ucapan terima kasih disampaikan kepada Bapak Prof. Komar Sumantadinata, Dr. Muhammad Zairin Jr. dan Dr. Odang Carman atas petunjuknya selama percobaan ini dilakukan.

\section{DAFTRAR PUSTAKA}

Alderdice, D.F. 1988. Osmotic and ionic regulation in teleost eggs and larva. In: Hoar, W.S. and Randall, D.J. (Eds.). Fish Physiology. Vol. XIA. Academic Press, New York. p. 163-242.

Arma, N.R., L. Muyati, K. Sumantadinata, M. Zairin Jr, dan H. Arfah. 1995. Pengaruh pemberian hormon 17x- 
metiltestosteron secara oral pada induk ikan gapi (Poecilia reticulata Peters) strain tuxedo terhadap jenis kelamin keturunannya. Jurnal Penelitian Perikanan Indonesia I (3):74-81.

Axelrod, H.R. 1971. Breeding Aquarium Fishes. Book 2. T.F.H. Publication Inc. Ltd. The British Crown Colony of Hongkong. $352 \mathrm{pp}$.

Baker, I.J., Solar, I.I., and Donaldson, E.M. 1988. Masculinization of chinook salmon Onchorhynchus tshawytscha) by immersion treatments using $17 \alpha$ methyltestosterone around the time of hacthing. Aquaculture 72: 359-367.

Bird, P. 1986. Characins and related species. In: Gilbert, $\mathrm{J}$. and Legge, R. (Eds.). The Complete Aquarist's Guide to Freshwater Tropical Fishes, Peter T. Low. Grafica Reunidas, Madrid. p. 54-79.

Donaldson, E.M. and Benfey, T.J. 1987. Current status of induced sex manipulation. In Proceeding of third international symposium on reproductive physiology of fish. St. John's, Newfounland. p. 108-119.

Guerrero, R.D. and Shelton, W.L. 1974. An acetocarmine squash method for sexing juvenile fishes. Progressive Fish Culturist 36:56

Hepher, B and Pruginin, Y. 1981. Commercial Fish Farming. John Willey and Sons, New York. 261 pp.

Hunter, G.A and Donaldson, E.M. 1983. Hormonal sex control and its application to fish culture. In: Hoar, W.S. and Randall, D.J. (Eds.). Fish Physiology. Vol. IX B. Academic Press, New York, p. 223-291.

Komen, J., Lodder, P.A.J., Huskens, F., Richter, C.J.J. and Huisman, E.A. 1989. Effects of administration of $17 \alpha$ methyltestosterone and 17-estradiol on gonadal development in common carp (Cyprinus carpio). Aquaculture 78:349-363

Lingga, P dan Susanto, H. 1991. Ikan Hias Air Tawar Seri Perikanan. Penebar Swadaya, Jakarta. 235 pp.
Martin, C.R. 1979. Texbook of endocrine physiology. Oxford University Press, New York. 462 pp

Matty, A. J. 1985. Fish Endocrinology. Croom Helm, London and Sydney. 259 pp

Mills, D. 1986. You and your aquarium. The complete guide to collecting and keeping aquarium fishes. Dorling Kindersley, London. 288 pp.

Mirza, J.A. and Shelton, W.L. 1988. Induction of gynogenesis and sex reversal in silver carp. Aquaculture 68:1. 14

Nagy, A., Beresenyi, M., and Csanyi, V. 1981. Sex reversal in carp. Cyprinus carpio by oral administration of $17 \alpha$-methyltestosterone. Canadian Journal of Fisheries and Aquatic Science 38:725-728

Petrovicky, I. 1988. Aquarium Fish of the World. Hamlyn Publishing Group Ltd., London. 499 pp.

Piferrer, F. and Donaldson, E.M. 1989. Gonadal differentiation in salmon, Onchorhynchus kisutch, after a single treatment with androgen or estrogen at different stages during ontogenesis. Aquaculture 77:251262.

Piferrer, F, and Donaldson, E.M. 1991. Dosage dependent differences in the effect of aromatizable androgen on the resulting phenotype of coho salmon (Oncorhynchus kisutch). Fish Physiology and Biochemistry 9: 145-150

Piferrer, F., Carillo, M., Zanuy, S., Solar, I.I. and Donaldson. E.M. 1994. Induction of sterility in coho salmon (Onchorhynchus kisutch) by androgen immersion before first feeding. Aquaculture 119:409-423.

Simone, D.A. 1990. The effects of the syntetic steroid $17 \alpha$-methyltestosterone on the growth and organ morphology of the channel catfish (Ictalurus punctatus). Aquaculture 8:81-93

Yamazaki, F. 1983. Sex control and manipulation in fish. Aquaculture 33: 329-354 